Cahiers $d u$ MONDE RUSSE

\section{Cahiers du monde russe}

Russie - Empire russe - Union soviétique et États indépendants

$59 / 1 \mid 2018$

varia

\title{
In memoriam Michel Aucouturier (1933-2017)
}

\section{Jean Bonamour}

\section{OpenEdition}

Journals

Édition électronique

URL : http://journals.openedition.org/monderusse/10306

DOI : 10.4000/monderusse. 10306

ISSN : $1777-5388$

Éditeur

Éditions de l'EHESS

\section{Édition imprimée}

Date de publication : 1 janvier 2018

Pagination : 159-160

ISBN : 978-2-7132-2745-5

ISSN : $1252-6576$

\section{Référence électronique}

Jean Bonamour, «In memoriam Michel Aucouturier (1933-2017)», Cahiers du monde russe [En ligne], 59/1 | 2018, mis en ligne le 01 janvier 2018, consulté le 06 janvier 2021. URL : http:// journals.openedition.org/monderusse/10306 ; DOI : https://doi.org/10.4000/monderusse.10306 


\section{IN MEMORIAM MICHEL AUCOUTURIER (1933-2017)}

Comment ne pas voir en Michel Aucouturier le type accompli du grand universitaire?

Je ne retracerai pas ici le détail de son « cursus honorum », qu'on retrouvera dans les excellents « Mélanges » en son honneur, publiés, comme il se devait, par l'Institut d'Études slaves. Il suffira de dire que Michel, jeune normalien, fut, avec Claude Frioux, le premier boursier en URSS, puis assistant de Pierre Pascal à La Sorbonne, bientôt professeur à l'université de Genève, puis à la Sorbonne. Cela sans visée d'ambition, sans stratégie, à la mesure de ses mérites tôt reconnus.

À vrai dire, sa vocation fut une véritable prédestination que les événements avaient confirmée dès son jeune âge. C'est ainsi que le père de Michel, Gustave Aucouturier, lui-même traducteur de talent, put en qualité de correspondant de l'agence France-Presse passer quelque mois avec sa famille à Moscou à la faveur de la brève détente qui suivit la guerre (septembre 1945-juin 1946). Rare privilège pour le jeune Michel qui s'initia au russe avec les gamins de son âge dans une cour moscovite (l'école lui demeurant inaccessible en dépit de la détente). Initiation qui eut lieu à partir du tchèque, car son père, lors d'un séjour en Tchécoslovaquie, avait épousé une jeune Tchèque, et c'est le tchèque qui était la langue pratiquée par la famille.

Éducation « cosmopolite » donc, où le russe et sa littérature eurent la première place sans que les autres champs d'études fussent délaissés. Outre le domaine tchèque à propos duquel il était souvent sollicité et souvent publié, il étendit ses curiosités à la plupart des littératures slaves. Arrivé à Genève, il mit en chantier un vaste cours de slavistique qui resta inédit.

Les travaux de Michel Aucouturier couvrent trois principaux domaines : l'un d'eux est la théorie de la littérature qui répondait chez lui à la fois à la formation philosophique du khâgneux, à un goût des idées et des débats, et aussi à une attirance pour les théoriciens russes, formalistes en particulier, qu'il connut, semble-t-il, durant son premier séjour à Moscou, sans oublier, naturellement, le cercle des linguistes de Prague et Roman Jakobson. J'imagine qu'il y eut là une véritable révélation pour le jeune boursier, l'université française ignorant largement à l'époque les travaux de théorie littéraire en cours dans l'Europe de l'Est, Allemagne comprise. 
En tout cas cette thématique fut dans l'œuvre de Michel une constante, comme en témoigne le sujet choisi pour sa thèse de doctorat « Les problèmes théoriques de la critique littéraire marxiste en Russie de 1888 à 1932 ». Les dates choisies suggèrent qu'il s'agit, à partir des racines mêmes de ce qui deviendra la critique littéraire soviétique, de mieux comprendre son rôle dans l'évolution du processus littéraire, qui, ici encore, demeure l'objet d'étude fondamental.

Le nom de Michel Aucouturier est bien connu d'un large public cultivé par ses traductions de la poésie russe et par celles de Tolstoj (La traduction du Docteur Jivago étant une œuvre collective à laquelle il a naturellement participé).

Il est remarquable que l'un et l'autre domaines, plus encore que des choix intellectuels, ont été pour lui des choix de vie. On est frappé de la constance quasi monacale que suppose la fidélité aux choix de ce grand travailleur. De l'adolescence à la mort il a construit et enrichi sa vie intérieure par et dans la poésie russe et dans ce qu'on pourrait appeler un tolstoïsme personnel, évidemment exempt de tout sectarisme. À cela s'ajoutait sa piété filiale. Gustave Aucouturier, russisant et traducteur à la langue impeccable, ne pouvait être qu'un exemple pour son fils, qui s'est naturellement inscrit dans ses pas, collaborant avec lui à l'occasion chez Gallimard. Les nombreuses traductions de Tolstoj qui parurent chez le même éditeur durant les dernières années du fils, par la qualité de la langue et la précision du commentaire historique, évoquent toujours la présence secrète du père.

Les traductions poétiques, sans doute la plus belle réussite de Michel, ont rallié les suffrages des lecteurs français aussi bien que ceux des spécialistes russes. Outre le talent, elles sont le fruit d'une lente maturation et d'immenses lectures, à la mesure de l'érudition des grands poètes de l' « Âge d'argent». Soulignons que ce travail solitaire a toujours enrichi un enseignement en séminaires, dans lequel ont été formés des disciples, traductrices et traducteurs de talent grâce auxquels l'œuvre de l'enseignant survivra, en même temps que le souvenir de l'homme.

Outre ses qualités pédagogiques de clarté et de rigueur, ses qualités humaines lui valaient en effet l'affection de ses étudiants : son indéfectible bienveillance, sa disponibilité en faisaient un maître aussi proche qu'il était respecté pour sa compétence. Ceux qui ont eu le privilège d'être son collègue peuvent témoigner de son inlassable dévouement à son métier dans les multiples fonctions qu'il a assumées (administration, organisation de colloques, secrétariat de la Société des Amis de Léon Tolstoï, nombreuses participations orales et écrites à des colloques, conférences, etc. etc.)

Michel a su garder ces immenses et rares qualités jusque dans les dernières années, alors que le sort le frappait avec une extrême cruauté dans ses êtres les plus proches. Le reste ne peut être que douloureux silence. 